\title{
A numerical approach for the modelling of forming limits in hot incremental forming of AZ31 magnesium alloy
}

\author{
Davide Campanella $^{1} \cdot$ Gianluca Buffa $^{1} \cdot$ Ernesto Lo Valvo ${ }^{2} \cdot$ Livan Fratini $^{1}$
}

Received: 23 December 2020 / Accepted: 7 April 2021 / Published online: 22 April 2021

(C) The Author(s) 2021

\begin{abstract}
Magnesium alloys, because of their good specific material strength, can be considered attractive by different industry fields, as the aerospace and the automotive one. However, their use is limited by the poor formability at room temperature. In this research, a numerical approach is proposed in order to determine an analytical expression of material formability in hot incremental forming processes. The numerical model was developed using the commercial software ABAQUS/Explicit. The JohnsonCook material model was used, and the model was validated through experimental measurements carried out using the ARAMIS system. Different geometries were considered with temperature varying in a range of $25-400{ }^{\circ} \mathrm{C}$ and wall angle in a range of $35-60^{\circ}$. An analytical expression of the fracture forming limit, as a function of temperature, was established and finally tested with a different geometry in order to assess the validity.
\end{abstract}

Keywords Incremental forming $\cdot$ Magnesium alloys $\cdot$ Numerical simulation $\cdot$ Fracture forming limit

\section{Introduction}

The growing demand for reduced pollution due to emissions from transport systems has motivated research towards the development of high-strength lightweight alloys with the intent to reduce the structural weight of vehicles and, as a consequence, the fuel consumption.

With this aim, among the materials and manufacturing processes most studied in recent decades, magnesium alloys and incremental forming (IF) of sheet metal parts certainly stand out; the former can be considered a good substitute to aluminum alloys in structural applications due to their very low density combined with good strength. As the latter is

Davide Campanella

davide.campanella@unipa.it

Gianluca Buffa

gianluca.buffa@unipa.it

Livan Fratini

livan.fratini@unipa.it

1 Department of Engineering, University of Palermo, viale delle Scienze, 90128 Palermo, Italy

2 Department. of Architecture, University of Palermo, viale delle Scienze, 90128 Palermo, Italy concerned, Filice et al. [1] showed that IF can be considered as an effective alternative to traditional sheet stamping to produce small batches of metal alloy components.

Incremental sheet forming can be successfully used in the aerospace as well as in the automotive sector, for which there is a high demand for spare parts and prototypes, and for which the use of magnesium alloys is continuously increasing.

In the past, the application of magnesium alloys was limited by its high reactivity and very low electrochemical potential, subjecting it to corrosion. In recent years, this problem has been partly overcome by the use of magnesium alloyed with aluminum, zinc and manganese, e.g., AZ31B, as studied by Franchitti et al. [2], who focused on the optimization of superplastic free forming test of an AZ31 magnesium alloy sheet. However, Agnew and Duygulu [3] have indicated that one of the reasons why the use of these alloys is still not particularly widespread is their low ductility and cold workability, as the compact hexagonal crystal structure limits the number of sliding surfaces. Neugebauer et al. [4] overcame this problem using high-temperature processing, as the increase of temperature favors the creation of new sliding surfaces, enhancing the formability of the material.

Pellegrini et al. [5] carried out tensile tests on AZ31B magnesium alloy samples at different temperatures and deformation speeds. The analysis of the fracture surface of the specimens revealed that a better and uniform recrystallized 
structure could be obtained at low and intermediate strain rates, at both $250{ }^{\circ} \mathrm{C}$ and $300{ }^{\circ} \mathrm{C}$.

Incremental hot forming, utilizing various heating systems, has been investigated in a few papers during recent years. The study carried out by Palumbo and Brandizzi [6] proved friction and electric heating to be much more flexible as well as economical in terms of equipment costs. A few different materials have been studied in literature. Ti-6Al-4V sheet was formed using electric hot incremental forming by Fan et al. [7] at temperatures ranging between 500 and $600{ }^{\circ} \mathrm{C}$. A thin layer of Ni-MoS2 was deposited on the sheet with the double aim to enhance the surface finish and protect from oxidation. The results indicated that, at the selected temperatures, higher dimensional accuracy can be achieved in the forming process of the titanium sheet. Vahdani et al. [8] experimentally studied the effects of a few process parameters, i.e., electric current, vertical pitch and feed rate, on the maximum height of truncated cones produced with varying wall angles, through electric hot incremental sheet forming (EHISF) of DC01 steel, AA6061 aluminum alloy and Ti-6Al-4V titanium alloy sheets. Major findings showed that the electric current was the most influential parameter on the formability of the Ti$6 \mathrm{Al}-4 \mathrm{~V}$ titanium sheet. Whereas, in the case of EHISF of the DC01 sheet, the formability varied depending on the feed rate as well as the type of lubricant used.

A study of Shi et al. [9] focused on EHISF with the aim to increase the dimensional accuracy of pyramid frustums made out of low carbon steel, finding that proper choice of a helical tool can prevent discharge phenomenon during the forming process.

Ambrogio et al. [10] authored one of the first papers on incremental hot forming of magnesium alloys, demonstrating the feasibility of the process and highlighting that the tool diameter has a negligible effect on formability. Zhi-guo et al. [11], studying the warm single-point incremental forming (SPIF) process, observed a ductile behavior starting at a temperature of $250^{\circ} \mathrm{C}$. Xu et al. [12] compared two heating systems, namely resistance and frictional stir heating, for different geometries. The obtained results indicated that resistance heating allowed the sheet temperature to increase at a faster rate with respect to frictional heating being less dependent on the geometry of the part. More recently, the same authors [13] studied double-sided electrically assisted incremental sheet forming (E-ISF) of truncated cones made out of AZ31B, finding that both surface finish and geometrical accuracy can be successfully improved with this technique. Zhang et al. [14] investigated a key aspect of warm negative incremental forming of magnesium alloys, i.e., the lubricant. They found that both nano- $\mathrm{K}_{2} \mathrm{Ti}_{4} \mathrm{O}_{9}$ whisker enhanced solid lubrication film and solid graphite gave satisfying results at both room and high temperature due also to the self-lubrication effect.

As far as the numerical simulation of EHISF of magnesium alloys is considered, a very limited number of papers is found in the literature. Ji and Park [15] modeled the production of
AZ31 truncated cones through a progressive EHISF forming technique with the aim to maximize the forming angle. The numerical model, developed in a PAM-STAMP environment, allowed the analysis of the deformation confirming the process mechanics observed in the experiments. Although interesting results were found by Nguyen et al. [16] about the variation of the forming limit diagram (FLD) curve with temperature, it is noted that the temperature range utilized was limited to 20-250 ${ }^{\circ} \mathrm{C}$. The test data assisted in the establishment of a springback and formability prediction analysis model.

Nguyen et al. [17] focused the attention on rotational incremental forming. ABAQUS was used to model the process, and a combined kinematic/isotropic hardening model, with a Johnson-Cook fracture model, was adopted to study the formability of square pyramids produced with varying tool down step and radius. Even in this case, due to the nature of the heat source, i.e., friction at the contact tool-sheet, the temperature range was limited to $100-141{ }^{\circ} \mathrm{C}$.

Based on the above reported literature analysis, it arises that, for the hot incremental forming process, a lack of knowledge exists in the determination of the formability limits of magnesium alloys over a wide range of temperature. In fact, an analytical formulation of the formability can be of help in the design of the process, both from the experimental and numerical points of view.

In the current paper, the authors studied the behavior and formability limit of the AZ31B magnesium alloy at temperatures ranging between room temperature and $400{ }^{\circ} \mathrm{C}$. Heating coils were used to increase the sheet temperature to the desired temperature. The research was developed moving in two directions, with experimental field tests on the one hand, and numerical analysis, utilizing the commercial finite element software ABAQUS/CAE Explicit, on the other. In particular, the followed approach was as follows: (i) experimental tests on truncated cone shape with varying temperature and wall angle; (ii) numerical simulations using the same process conditions to assess the FE model and the JC fracture model validity; (iii) numerical simulations using truncated pyramid shape in order to collect different distributions of major and minor strain; (iv) fracture forming limit (FFL) calculation on the basis of the numerical model results; (v) assessment of the determined analytical formulations on a "flower-shaped" case study.

\section{Material and methods}

\subsection{Experimental tests}

For the experiments, $330 \times 260 \mathrm{~mm}$ AZ31B magnesium alloy sheets, $1.2 \mathrm{~mm}$ in thickness, were used. Table 1 reports the chemical composition of the alloy.

The incremental hot forming tests were carried out by clamping the sheet metals on a heating chamber (Fig. 1). 
Table 1 Chemical composition (wt\%) of base metal AZ31B magnesium alloy

\begin{tabular}{llllllll}
\hline $\mathrm{Al}$ & $\mathrm{Mn}$ & $\mathrm{Zn}$ & $\mathrm{Cu}$ & $\mathrm{Ni}$ & $\mathrm{Si}$ & $\mathrm{Fe}$ & $\mathrm{Mg}$ \\
\hline 3.0 & 2.0 & 1.0 & 0.05 & 0.005 & 0.1 & 0.005 & Balance \\
\hline
\end{tabular}

Inside the chamber, an electrical resistance was used as heat source, and the whole structure was filled with rock wool. In order to reduce the thermal dispersion and therefore to improve the insulation of the chamber itself, insulating silicone was used (Fig. 1).

Process temperature was controlled by using two K-type thermocouples (Chromel/Lumel): one was placed on the bottom surface of the sheet $\left(\mathrm{T}_{1}\right)$, while the other inside the heating chamber $\left(\mathrm{T}_{2}\right)$. The control system (Fig. 2) consists of an Arduino UNO microcontroller with ATMEGA 328P processor, connected via Serial Peripheral Interface (SPI) to two MAX6675 thermocouple transducers, equipped with cold junction and digital output with a 12-bit resolution. Graphite spray was used as a lubricant for the tests (Fig. 2).

Depending on the temperature measured by the thermocouples, the system operated two mechanical relays connected to the heating coils. The target temperature was selected using a dedicated potentiometer. The system also transferred, via serial port, real-time data to a computer for acquiring and recording temperature changes during the process, with a sampling frequency of $5 \mathrm{~Hz}$. The analyzed temperature ranged between room temperature $\left(25^{\circ} \mathrm{C}\right)$ and $400{ }^{\circ} \mathrm{C}$, considering a temperature increase step of $50{ }^{\circ} \mathrm{C}$ from $200{ }^{\circ} \mathrm{C}$ onwards. It is worth noticing that, for the AZ31 magnesium alloy, the temperature of $400{ }^{\circ} \mathrm{C}$, at which all the possible slip systems are activated, can be considered the one corresponding to maximum formability as demonstrated by Bohlen et al. [18].
The experimental tests were carried out on a conical frustum geometry with varying wall angle and temperature. The geometrical and technological parameters utilized are reported in Table 2. Each test was repeated three times for result accuracy. The ARAMIS acquisition system was used to measure the formed part thickness. The experimental sheet thickness was acquired before and after the experimental tests in order to avoid in-process acquisition difficulties due to the hot clamping chamber (closed at the bottom). To overcome the difficulties encountered in the 3D acquisition due to the reflectivity of the sheet surface and the impossibility of using paints to cover the surface, a temperature resistant coating with a thickness of $5 \mu \mathrm{m}$ was applied on the bottom surface of the sheets to be processed.

\subsection{Numerical model}

The ABAQUS/Explicit@ commercial software was used for the simulation of the experimental process. The constitutive model and the fracture criterion were defined using the Johnson-Cook model (Eq. 1), where $T_{\mathrm{R}}$ is the room temperature and $T_{\mathrm{M}}$ is the melting temperature, and the Johnson-Cook fracture model (Eq. 2) where $\varepsilon_{\mathrm{f}}$ is equivalent plastic strain, $p$ is the average value of the three normal stresses and $q$ is the Von Mises equivalent stress. Material constants, taken from the paper by Abbassi et al. [19], are reported in Table 3 .

$$
\begin{aligned}
& \sigma=\left(A+B \varepsilon^{n}\right)(1+C \ln \varepsilon)\left[1-\left(\frac{T-T_{\mathrm{R}}}{T_{\mathrm{M}}-T_{\mathrm{R}}}\right)^{m}\right] \\
& \varepsilon_{f}=\left[D_{1}+D_{2} e^{\left(D_{3} \frac{p}{q}\right)}\right]\left[1+D_{4} \ln \varepsilon\right]\left[1+D_{5}\left(\frac{T-T_{\mathrm{R}}}{T_{\mathrm{M}}-T_{\mathrm{R}}}\right)\right]
\end{aligned}
$$

Fig. 1 a Actual device. b Schematic representation

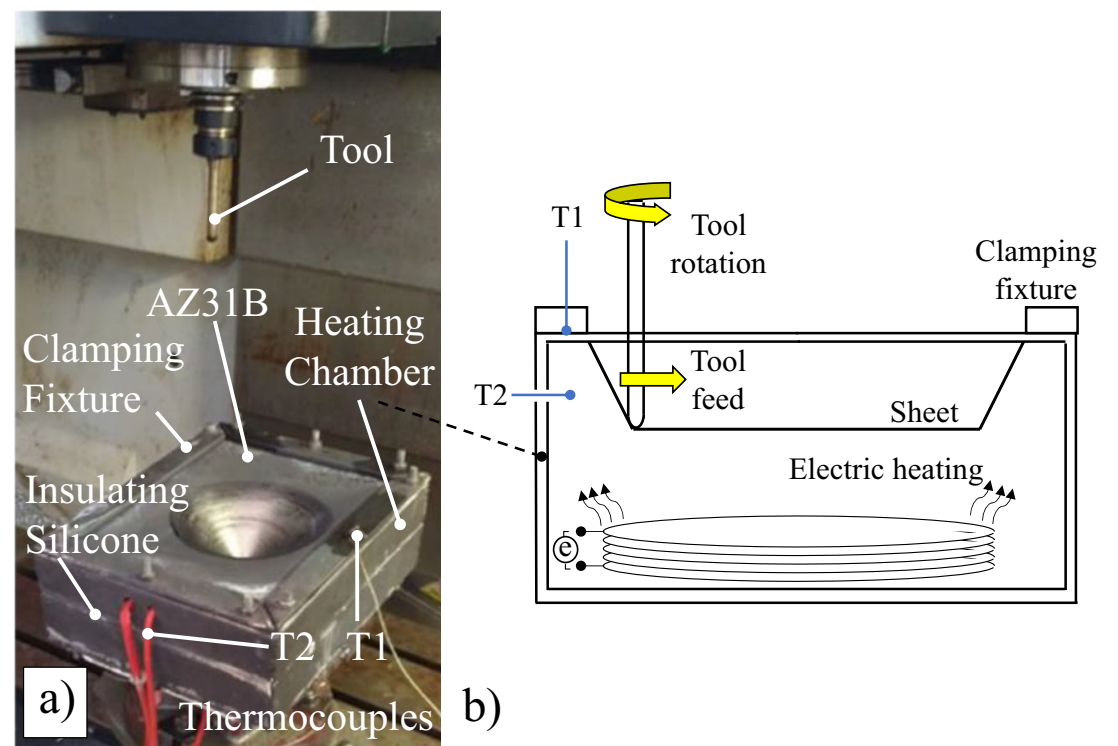


Fig. 2 The ARDUINO electrical circuit diagram used

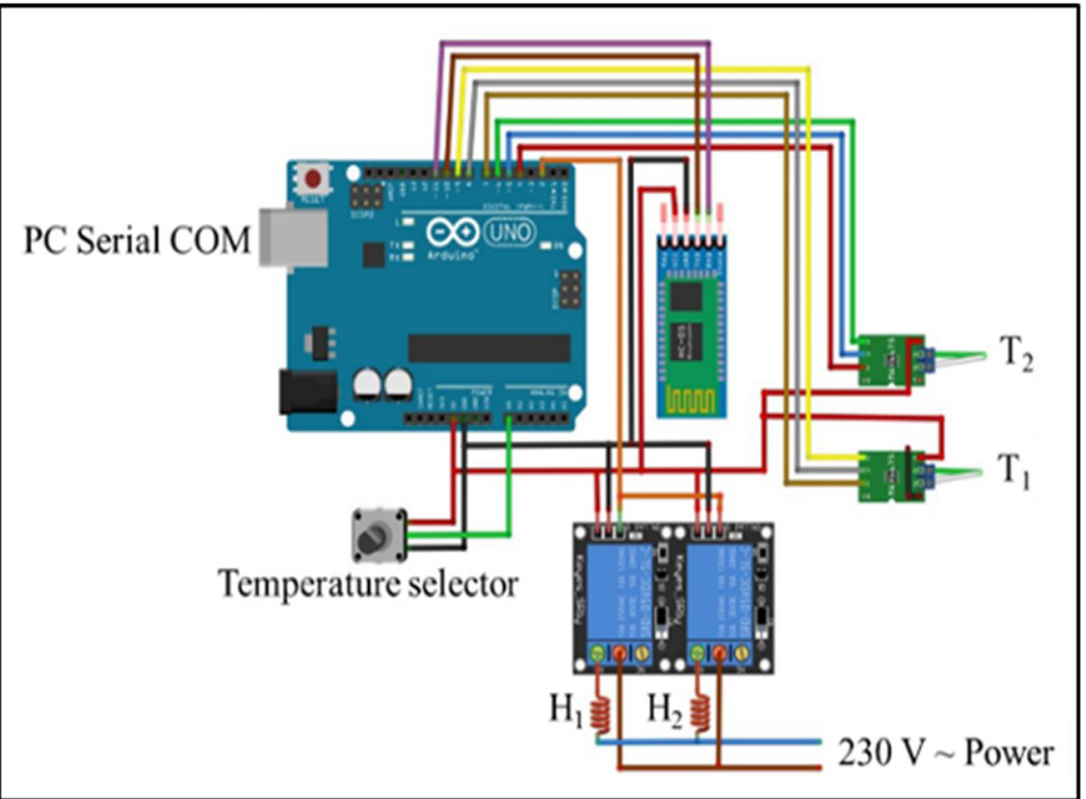

The sheet was modeled as a deformable object, using the shell type elements S4RT option (5 integration points through the thickness), with a thickness of $1.2 \mathrm{~mm}$, while the tool was modeled as a rigid element with a hemispherical shape having a diameter of $12 \mathrm{~mm}$. For the mesh of the sheet, about 12,000 elements were required. Furthermore, the element deletion option was activated in the Mesh option module and "status" in the field output menu to visualize the damage to the sheet once the threshold value of the Johnson-Cook fracture model was reached. Surface-to-surface contact with a friction coefficient assumed to be 0.05 was set.

Each simulation took approximately $20 \mathrm{~min}$ to complete on a PC with an Intel i7 processor.

The temperature of the tests was imposed by the Edit Boundary Condition function assuming an isothermal condition. The friction coefficient used was equal to 0.05 , and the mass scaling was fixed as 1000 . Besides the truncated cone, two additional tool paths, i.e., a truncated pyramid and a "flower"-shaped geometry, were modeled. Geometrical

Table 2 Main process geometrical and technological parameters

\begin{tabular}{ll}
\hline Parameter & Value \\
\hline Tool diameter $(\mathrm{mm})$ & 12 \\
Tool feed rate $(\mathrm{mm} / \mathrm{min})$ & 2000 \\
Tool vertical pitch $(\mathrm{mm})$ & 1 \\
Conical frustum major diameter $(\mathrm{mm})$ & 150 \\
Cone height $(\mathrm{mm})$ & 70 \\
Draw angle $\theta\left({ }^{\circ}\right)$ & $35-60$ \\
Temperature $\left({ }^{\circ} \mathrm{C}\right)$ & $25-400$ \\
\hline
\end{tabular}

details are shown in Fig. 3. All the tool paths were created using a spiral pattern (Fig. 3).

\section{Results}

\subsection{Experimental results and model validation}

Experimental tests were carried out for the truncated cone path with wall angles of $35^{\circ}, 40^{\circ}, 45^{\circ}, 50^{\circ}$ and $60^{\circ}$ at different temperatures. Figure 4 shows two typical conditions observed during the experimental tests: a sound part formed till the maximum height assigned obtained using a wall angle of $50^{\circ}$ and a temperature of $400{ }^{\circ} \mathrm{C}$ (see Fig. 4a) and a part for which early fracture occurred, obtained using a wall angle of $45^{\circ}$ and a temperature of $250{ }^{\circ} \mathrm{C}$ (see Fig. 4b).

Figure 5 reports the obtained process window: the tests that showed signs of fracture are labeled with an " $\mathrm{X}$ " and the sound tests with a " $\Delta$ " (Fig. 5).

Table 3 Johnson-Cook parameters for AZ31B

Johnson-Cook constitutive model

\begin{tabular}{lllll}
\hline$A(\mathrm{MPa})$ & $B(\mathrm{MPa})$ & $n$ & $C$ & $m$ \\
\hline 172 & 360.73 & 0.45592 & 0.092 & 0.95 \\
Johnson-Cook fracture model & & & \\
$D_{1}$ & $D_{2}$ & $D_{3}$ & $D_{4}$ & $D_{5}$ \\
-0.35 & 0.6025 & -0.4537 & 0.206 & 7.2 \\
\hline
\end{tabular}


Fig. 3 a Truncated pyramid. b "Flower"-shaped geometry modeled

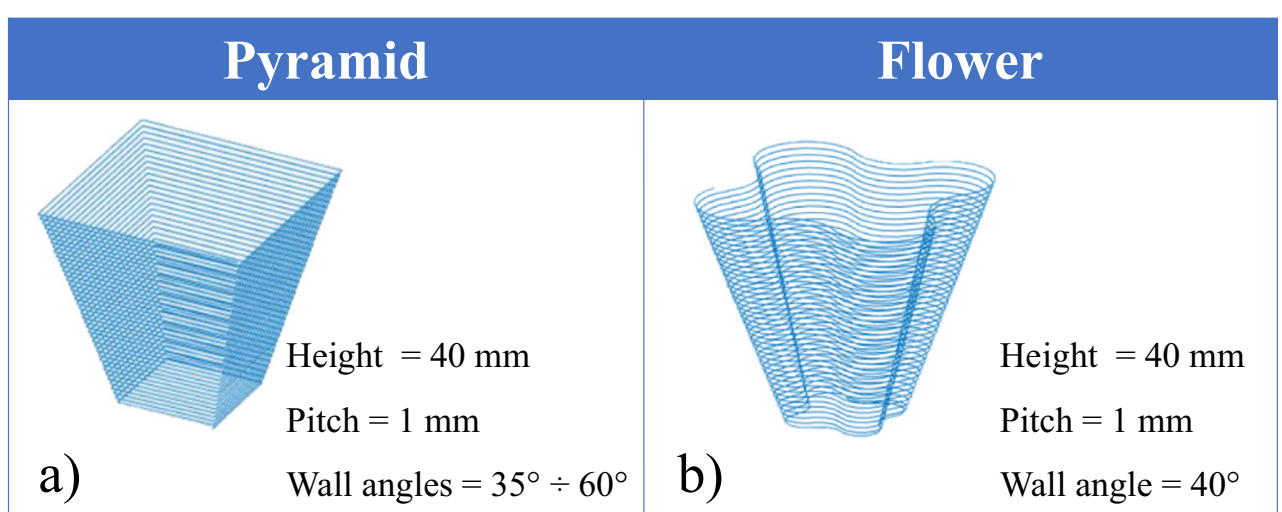

It is seen that, at room temperature, even using the smallest of the considered wall angle values, i.e., $35^{\circ}$, the cone cannot be formed to the assigned height. The latter wall angle could be obtained only with a temperature of $250{ }^{\circ} \mathrm{C}$ (or higher), while the maximum wall angle of a sound part was $50^{\circ}$, obtained at $400{ }^{\circ} \mathrm{C}$.

The numerical model was validated by comparing, for each of the considered case studies obtained by varying temperature and wall angle, the thinning distribution experimentally measured through the ARAMIS, non-contact, Digital Image Correlation system and the one numerically calculated.

The parts were initially coated with a white paint. Once dry, small droplets of black paint were sprayed onto the parts; after which, the part was scanned by the Aramis System. The Aramis System allows one to measure the deformations occurring in a part by calculating the displacements of the black dots with respect to their initial positions before the experimental procedure. This displacement can be used as a function for calculating various properties, like thickness in the case of the current research.
In Fig. 6, the comparison between the experimental and numerical data has been reported for the case study characterized by $400{ }^{\circ} \mathrm{C}$ and a wall angle of $50^{\circ}$. The $x$-axis indicates the curvilinear abscissa taken on the cross section of the produced part passing through the center of the cone. As shown in Fig. 6a, thinning increases with increasing cone height. This is consistent with what was found by Mirnia and Shamsari [20], according to which the trend of the curve is strongly influenced by the major strain acting on the cone lateral surface, being the minor strain almost negligible (Fig. 6).

It is worth noticing that similar good agreement was also found for the other case studies. Figure 7 shows the case study characterized by a wall angle of $60^{\circ}$ and a temperature of 400 ${ }^{\circ} \mathrm{C}$, for which early fracture was obtained (see again Fig. 3 ).

It is seen that in the area in which the maximum level of the Johnson-Cook criterion was reached, the corresponding elements have been deleted. The forming height at which fracture occurs is $16 \mathrm{~mm}$ for both the experimental test and the numerical model. The thickness distribution was also observed along the profile at a given depth in order to investigate the possible
Fig. 4 Experimental tests results. a Temperature $400{ }^{\circ} \mathrm{C}$ and wall angle $50^{\circ}$. b Temperature $250^{\circ} \mathrm{C}$ and wall angle $45^{\circ}$

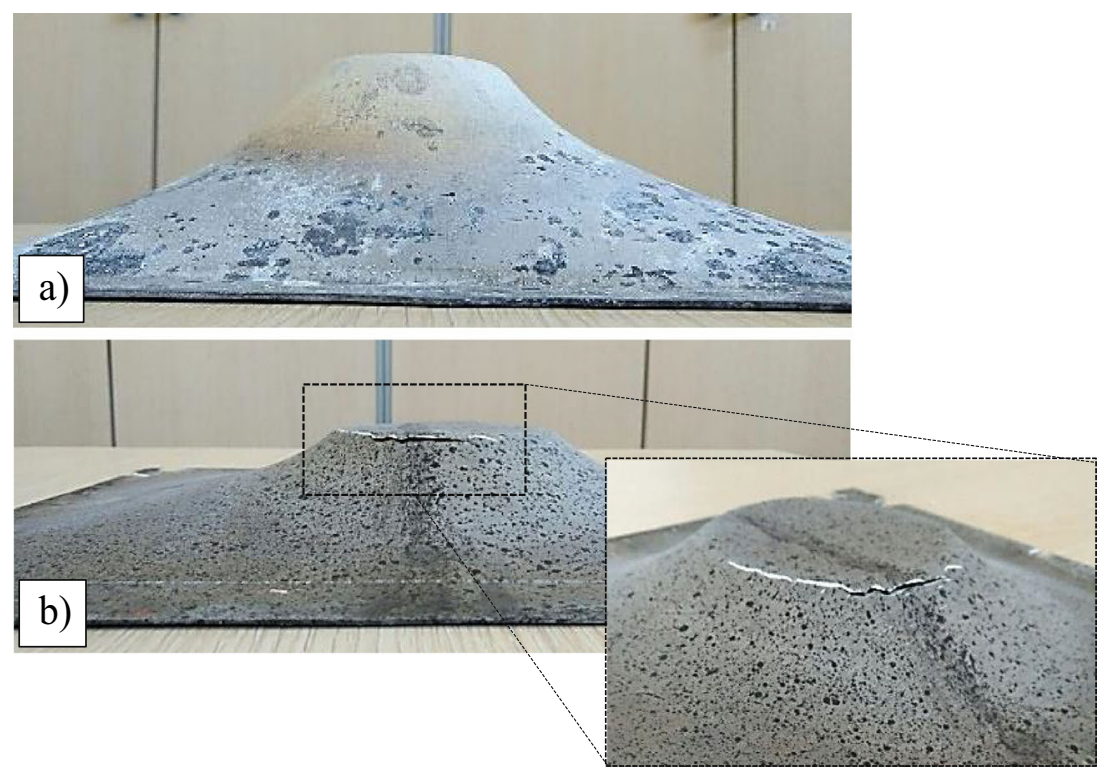




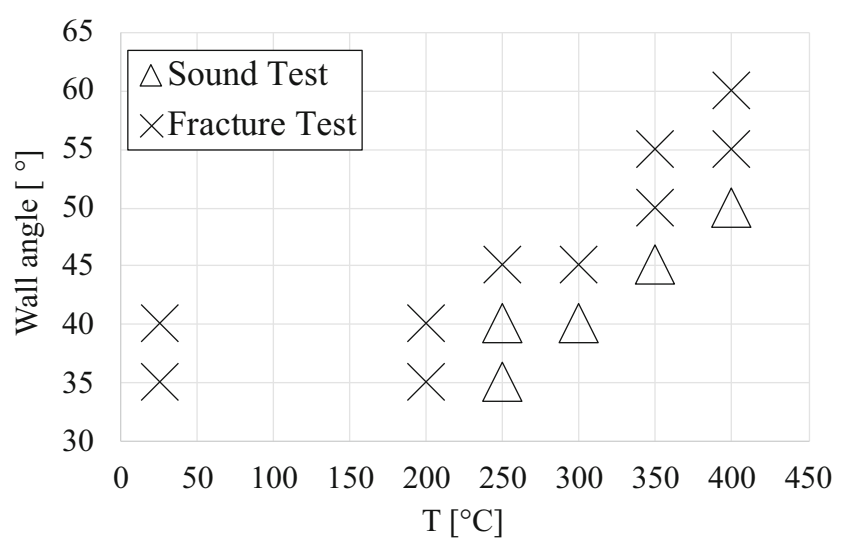

Fig. 5 Experimental campaign on cone frustrum: process window obtained with varying temperatures and wall angles

effects of the used rectangular clamping system geometry on the final part. The obtained results indicated no significant variation of the thickness due to the chosen clamping system (Fig. 7).

\subsection{Analytical FFL determination}

In order to determine an analytical expression of AZ31 formability, the effective plastic strain (referred as PEEQ) was analyzed.

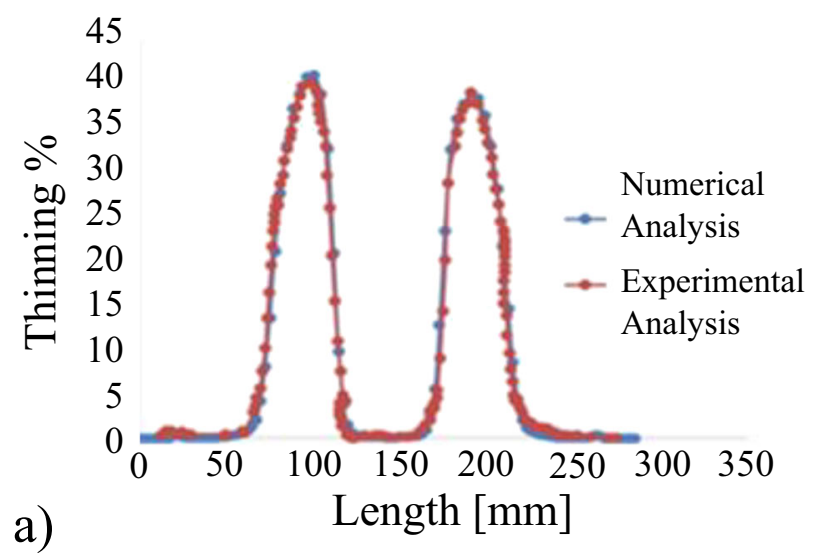

b)

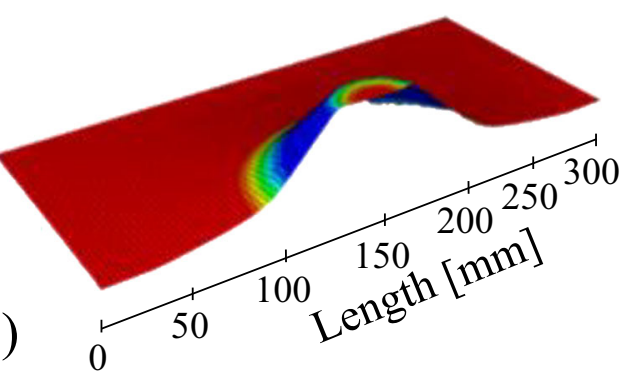

1.20
1.10
1.00
0.90
0.80
0.70

Fig. 6 a Comparison of experimental and numerical thinning. b Experimentally measured section in ARAMIS-temperature $400{ }^{\circ} \mathrm{C}$ and wall angle $50^{\circ}$

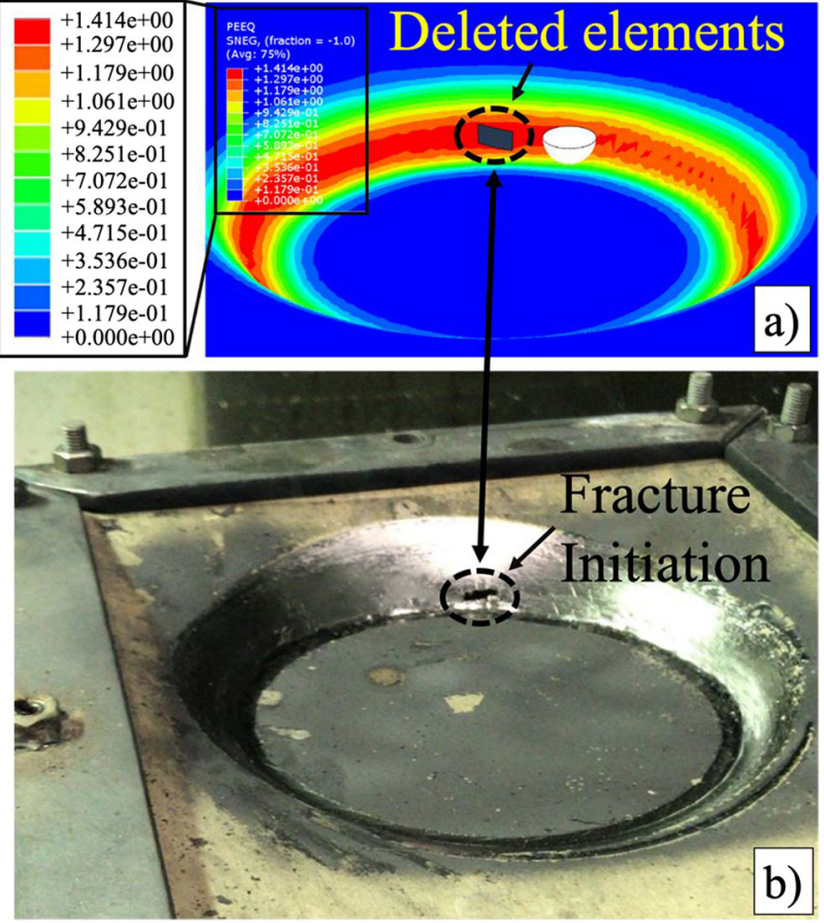

Fig. 7 a PEEQ distribution in numerical model. b Experimental test result-temperature $400^{\circ} \mathrm{C}$ and wall angle $60^{\circ}$

Figure 8 shows the thickness distribution and the PEEQ for the same case study considered in Fig. 6. It is noted that the PEEQ distribution has a specular profile with respect to the thickness, being maximum where minimum thickness is observed (Fig. 8).

This is one of the reasons why some researchers have used PEEQ as a sort of "formability index" as also mentioned by Shalin et al. [21]. An interesting observation can be made looking at the thickness distribution: different from what occurs in conventional SPIF (i.e., at room temperature), in warm conditions the part area characterized by minimum thickness is not close to the top surface of the sheet but is distributed quite evenly along the wall.

As observed by Soeiro et al. [22], when the material in the whole wall angle area participates to deformation, fracture occurs when maximum thinning is reached.

For each considered case study, a representing value of PEEQ was acquired. This corresponds to the maximum value in the case of safe conditions (e.g., 1.36 for the case study characterized by $50^{\circ}$ and $400{ }^{\circ} \mathrm{C}$, as shown in Fig. 8) or to the maximum value at fracture for process conditions for which the forming process could not be completed (e.g., 1.41 for the case study characterized by $60^{\circ}$ and $400{ }^{\circ} \mathrm{C}$, as shown in Fig. 7a). In this way, a threshold value was identified, indicating the maximum PEEQ that the material can undergo for a given temperature (fracture line), dividing the graph area in two main areas: a safe area (formability zone) and a failure one (fracture zone). From the curves reported in 
Fig. 8 Lateral view of the truncated cone. a Thickness distribution. b PEEQ distribution-temperature $400{ }^{\circ} \mathrm{C}$ and wall angle $50^{\circ}$
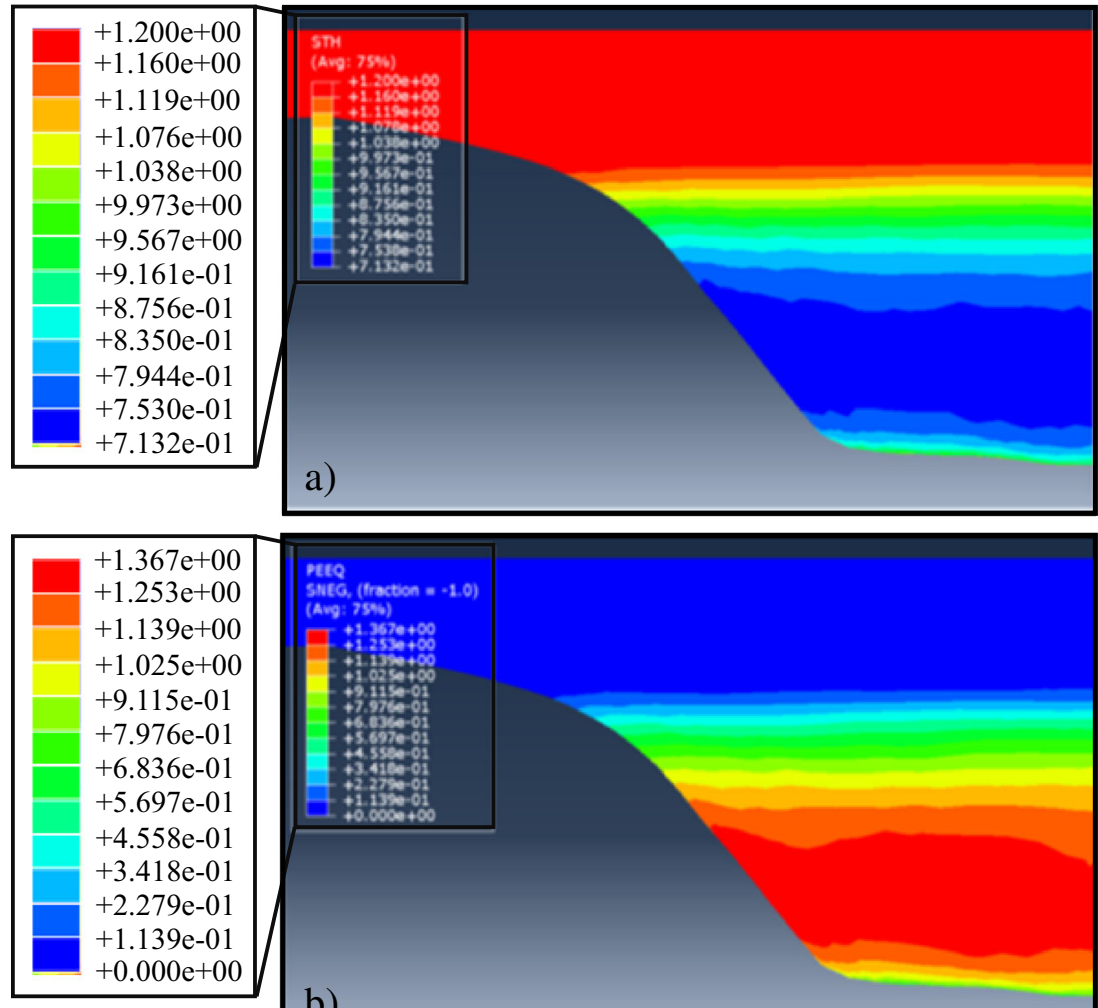

b)
Fig. 9, it can be seen that the amount of PEEQ that the considered material can tolerate increases with temperature. As an example, considering a wall angle of $45^{\circ}$, safe conditions cannot be reached until the temperature is equal or higher to 350 ${ }^{\circ} \mathrm{C}$, as a PEEQ of about 1.1 is needed in order to safely form the cone. It should be observed that the case studies characterized by (i) a wall angle of $40^{\circ}$ and a temperature of $250^{\circ} \mathrm{C}$ and (ii) a wall angle of $50^{\circ}$ and a temperature of $400^{\circ} \mathrm{C}$ should be considered as "borderline": although these process conditions are indicating as safe in the process window shown in

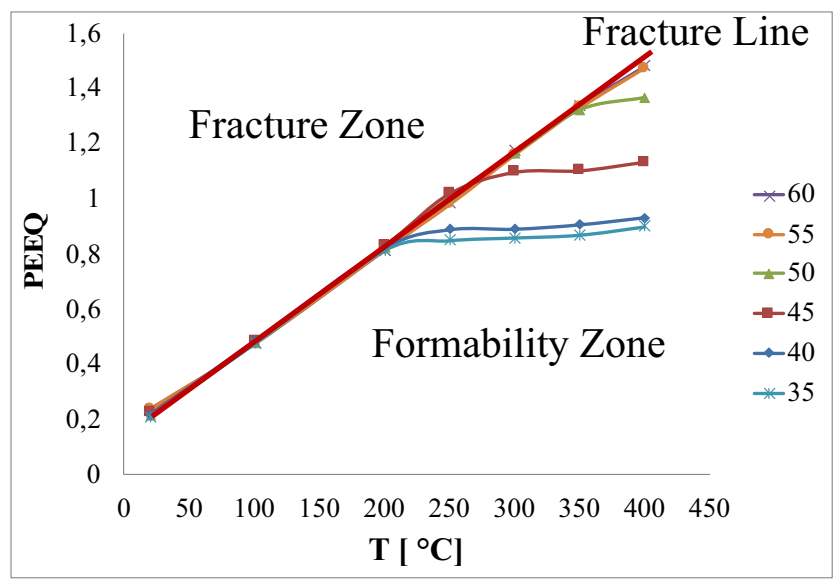

Fig. 9 PEEQ values as a function of temperature for the simulations carried out with different angles on the truncated cone geometry
Fig. 5, for both conditions only two over three specimens were actually sound, while the third showed a fracture. Both the process conditions show a PEEQ value only slightly below the threshold value, indicating that it could be considered a confidence band of about 0.03 for PEEQ (Fig. 9).

As observed by Soeiro et al. [22], for the cone geometry, the mechanical deformation is mainly characterized by the major strain rather than the minor strain and fracture occurs due to the growth of the major strains. Hence, in order establish a reliable analytical expression valid for every geometry of the part to be formed, the maximum deformation attainable at different temperatures should be evaluated for different geometries. In particular, a set of numerical simulations was run using a square base pyramid path. The truncated pyramid was chosen as, for this geometry, Isik et al. [23] showed that the major and minor strains are more balanced. Figure 10 represents a truncated pyramid with an angle of $40^{\circ}$ and a temperature of $300{ }^{\circ} \mathrm{C}$, where the thickness and PEEQ distributions are shown (Fig. 10).

The same approach followed for the determination of the curves shown in Fig. 9 for the truncated cones was followed for the pyramid (Fig. 11). It is noted that the values on the fracture line are the same as the ones found for the truncated cone (Fig. 11).

Once the deformation limit values for the two analyzed geometries were determined, the formability limit curves were plotted for the AZ31B alloy. Figure 12a shows the fracture 
Fig. 10 Truncated square pyramid. a Thickness distribution. b PEEQ distribution-temperature $300{ }^{\circ} \mathrm{C}$ and wall angle $40^{\circ}$

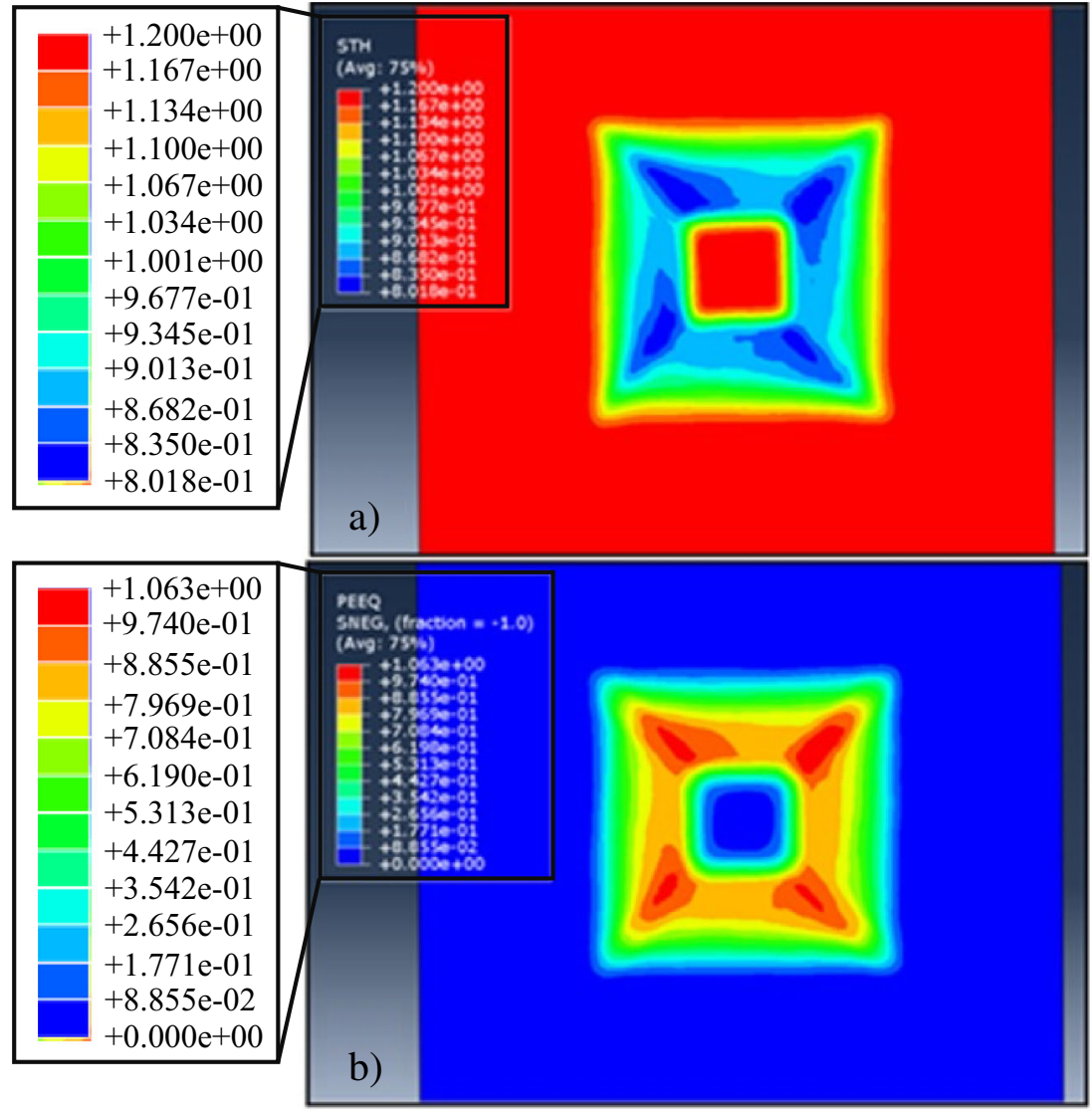

forming limit (FFL) obtained for the case study characterized by a temperature of $300^{\circ} \mathrm{C}$ and a wall angle of $40^{\circ}$. Figure $12 \mathrm{~b}$ shows the FFL curves obtained in the temperature range considered in this study. It is worth noticing that, although FLD curves are a tool of considerable importance in the design of sheet metal forming processes, several authors demonstrated that, because of the peculiar SPIF forming mechanics,

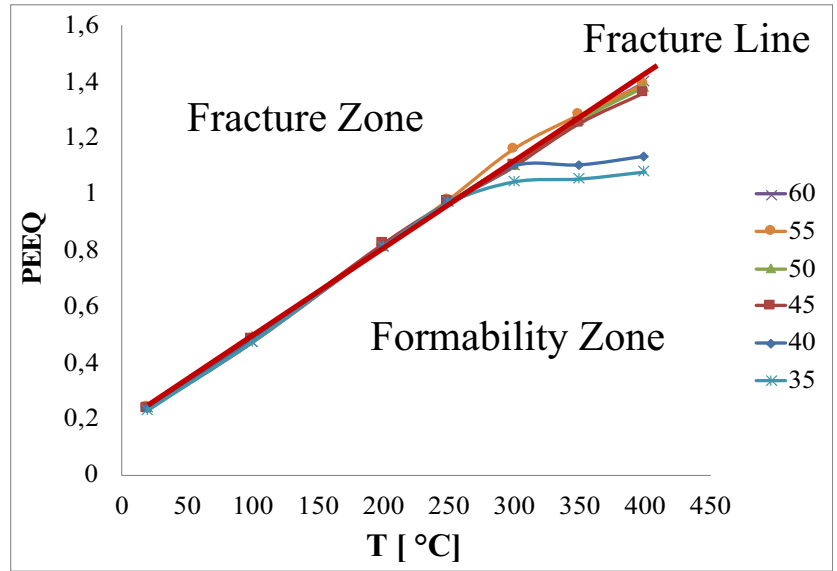

Fig. 11 PEEQ values as a function of temperature for the simulations carried out with different angles on the truncated square pyramid geometry

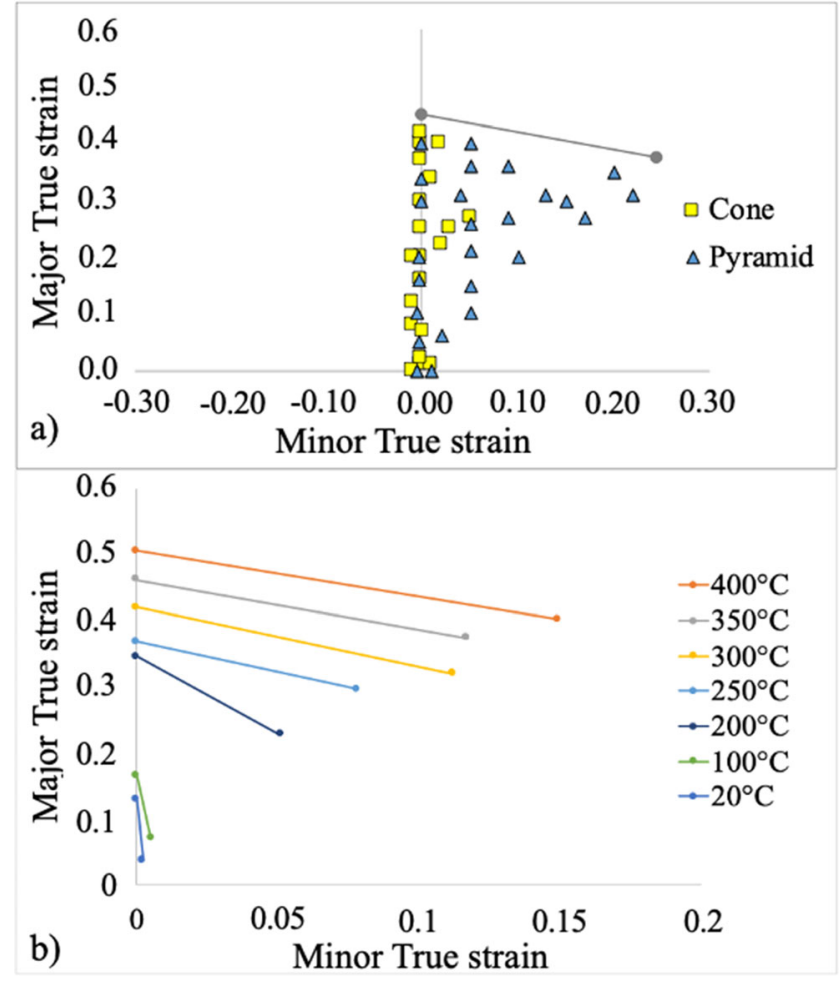

Fig. 12 a Fracture forming limit (FFL) obtained for the case study characterized by a temperature of $350{ }^{\circ} \mathrm{C}$ and a wall angle of $40^{\circ}$. b FFL curves obtained in the temperature range considered in this study 
considering the FFL instead of FLD is more appropriate [22-24] (Fig. 12).

A numerical regression was carried out in order to obtain an analytical expression (Eqs. 3 and 4) of the considered material formability in hot SPIF. Figure 13a, b shows the fitting curves for the $\mathrm{FFL}_{0}$ and the slope $(m)$, respectively (Fig. 13).

$\mathrm{FFL}_{0}(\mathrm{~T})=0.0011 \mathrm{~T}+0.0985$

$m(\mathrm{~T})=2 \mathrm{E}-06 \mathrm{~T}^{3}-0.0016 \mathrm{~T}^{2}+0.5158 \mathrm{~T}-55.814$

Finally, with the aim to assess the applicability of the obtained analytical formulation, a more complicated shape was considered. No sound part could be produced using this geometry with a wall angle of $40^{\circ}$. The best result was obtained at a temperature of $400{ }^{\circ} \mathrm{C}$, at which fracture occurred when the part height was $30 \mathrm{~mm}$. Figure 14 shows minor and major strains calculated at $300{ }^{\circ} \mathrm{C}$ and $400{ }^{\circ} \mathrm{C}$ for the abovementioned flower geometry, the truncated cone and the square pyramid, together with the limit curve. It is seen that all the points related to truncated cone and square pyramid lay below the limit curve, being closer to the latter at $\mathrm{T}=300^{\circ} \mathrm{C}$, while,

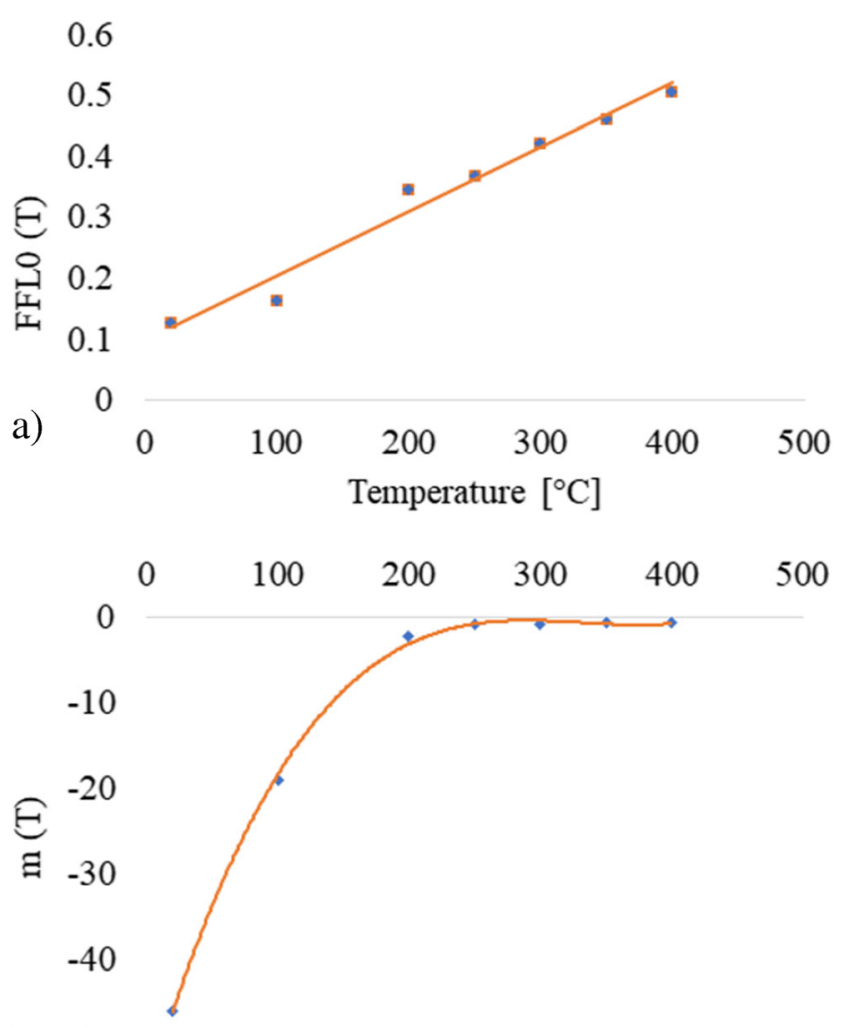

b) -50

Fig. 13 Fitting curves, as a function of temperature, for $\mathbf{a} \mathrm{FFL}_{0}$ and $\mathbf{b}$ slope $(m)$ of the FFL

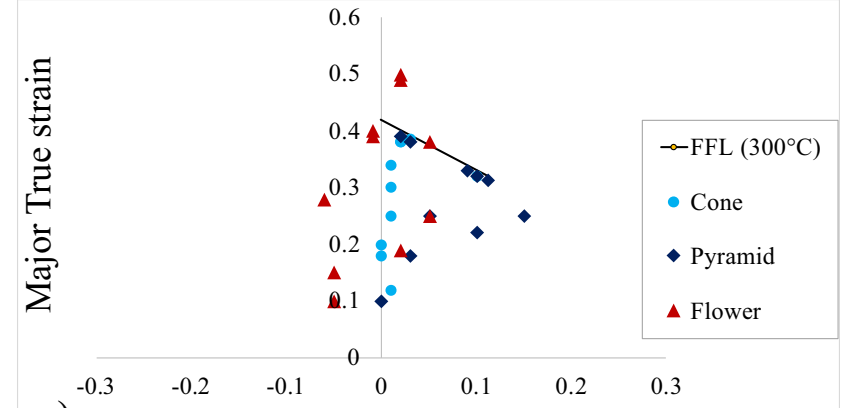

a) Minor True strain

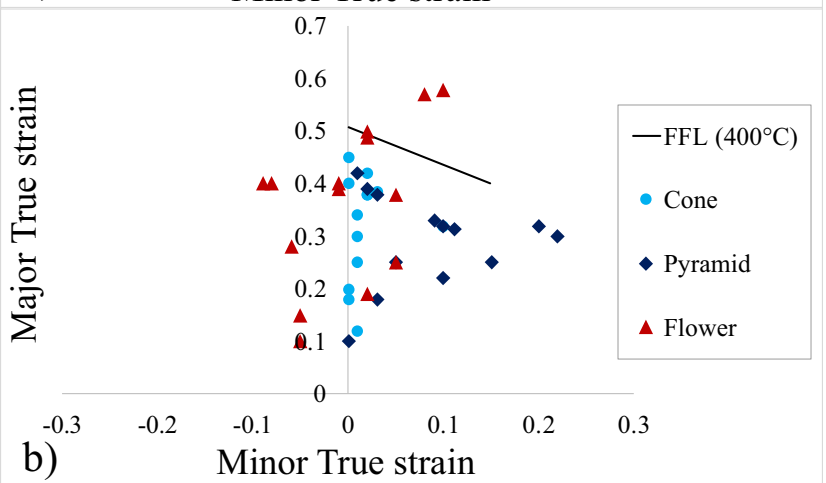

Fig. 14 FFL and major and minor strain distributions for the truncated cone, square pyramid and flower geometries at $\mathbf{a} T=30{ }^{\circ} \mathrm{C}$ and $\mathbf{b} T=$ $400{ }^{\circ} \mathrm{C}$

at both temperatures, points corresponding to the flower geometry are found above the curve, indicating the failure points (Fig. 14).

\section{Conclusions}

In the paper, a numerical approach was adopted in order to determine an analytical expression of the formability limit for the AZ31 magnesium alloy in EHISF. The sheets were heated by electrical resistance applied to the clamping fixture, and tests were carried out between room temperature and 400 ${ }^{\circ} \mathrm{C}$. A numerical model, once validated on frustrum cone geometry, was used to calculate the occurring strains for each case study obtained by the combination of two geometries, i.e., frustrum cone and square pyramid, and varying temperature and wall angle.

From the obtained results, it was observed a strict correlation between the PEEQ numerically calculated and the sheet thinning; a threshold value of PEEQ was identified for each considered temperature. Additionally, an analytical expression of the fracture forming limit curve, as a function of temperature, was identified.

The obtained analytical expression was used to assess the generalization capability of the proposed approach by considering a further case study defined by a "flower-shaped" 
geometry. For this geometry, no sound part could be produced, and points over the limit curve were found as expected.

Acknowledgements The authors would like to thank Prof. Salvatore Pasta for providing support with the numerical simulation software.

Author contribution DC carried out the experiment. DC and GB wrote the manuscript with support from Livan Fratini. ELV helped supervise the project, DC conceived the original idea and LF supervised the project.

Funding Open access funding provided by Università degli Studi di Palermo within the CRUI-CARE Agreement.

Availability of data and materials The authors confirm that the data supporting the findings of this study are available within the articles cited in the text and the references of the manuscript.

\section{Declarations}

Ethics approval and consent to participate Research participants were not subjected to harm in any ways whatsoever. The respect for the dignity of all the research participants had been prioritized, and full consent was obtained from the participants prior to the research study.

Consent for publication The authors consent to Springer the nonexclusive publication rights and warrant that their contribution is original and that they have full power to make this grant

Competing interests The authors declare no competing interests.

Open Access This article is licensed under a Creative Commons Attribution 4.0 International License, which permits use, sharing, adaptation, distribution and reproduction in any medium or format, as long as you give appropriate credit to the original author(s) and the source, provide a link to the Creative Commons licence, and indicate if changes were made. The images or other third party material in this article are included in the article's Creative Commons licence, unless indicated otherwise in a credit line to the material. If material is not included in the article's Creative Commons licence and your intended use is not permitted by statutory regulation or exceeds the permitted use, you will need to obtain permission directly from the copyright holder. To view a copy of this licence, visit http://creativecommons.org/licenses/by/4.0/.

\section{References}

1. Filice L, Fratini L, Micari F (2002) Analysis of material formability in incremental forming. CIRP Ann 51(1):199-202. https://doi.org/ 10.1016/S0007-8506(07)61499-1

2. Franchitti S, Giuliano G, Palumbo G, Sorgente D, Tricarico L (2008) On the optimisation of superplastic free forming test of an AZ31 magnesium alloy sheet. Int J Mater Form 1(SUPPL. 1): 1067-1070. https://doi.org/10.1007/s12289-008-0203-0

3. Agnew SR, Duygulu O (2003) A mechanistic understanding of the formability of magnesium: examining the role of temperature on the deformation mechanisms. Mater Sci Forum 419-422:177-188. https://doi.org/10.4028/www.scientific.net/MSF.419-422.177
4. Neugebauer R, Altan T, Geiger M, Kleiner M, Sterzing A (2006) Sheet metal forming at elevated temperatures. CIRP Ann 55(2): 793-816. https://doi.org/10.1016/j.cirp.2006.10.008

5. Pellegrini D, Ghiotti A, Bruschi S (2009) Microstructure phenomena and mechanical properties of AZ31B under warm forming conditions. Int J Mater Form 2(SUPPL. 1):275-278. https://doi.org/10. 1007/s12289-009-0607-5

6. Palumbo G, Brandizzi M (2012) Experimental investigations on the single point incremental forming of a titanium alloy component combining static heating with high tool rotation speed. Mater Des 40:43-51. https://doi.org/10.1016/j.matdes.2012.03.031

7. Fan G, Gao L (2014) Numerical simulation and experimental investigation to improve the dimensional accuracy in electric hot incremental forming of Ti-6Al-4V titanium sheet. Int $\mathrm{J}$ Adv Manuf Technol 72(5-8):1133-1141. https://doi.org/10.1007/ s00170-014-5769-8

8. Vahdani M, Mirnia MJ, Bakhshi-Jooybari M, Gorji H (2019) Electric hot incremental sheet forming of Ti-6Al-4V titanium, AA6061 aluminum, and DC01 steel sheets. Int J Adv Manuf Technol 103(1-4):1199-1209. https://doi.org/10.1007/s00170019-03624-2

9. Shi X, Gao L, Khalatbari H, Xu Y, Wang H, Jin L (2013) Electric hot incremental forming of low carbon steel sheet: accuracy improvement. Int J Adv Manuf Technol 68:241-247. https://doi.org/ 10.1007/s00170-013-4724-4

10. Ambrogio G, Filice L, Manco GL (2008) Warm incremental forming of magnesium alloy AZ31. CIRP Ann 57(1):257-260. https://doi.org/10.1016/j.cirp.2008.03.066

11. An Z-g, Dong Y, Qie J-j, Lu Z-1, Gao Z-y (2020) Effect of process parameters on formability of a AZ31 magnesium alloy thin-walled cylindrical part formed by multistage warm single-point incremental forming. Front Mater 7:151. https://doi.org/10.3389/fmats.2020. 00151

12. Xu D, Lu B, Cao T, Chen J, Long H, Cao J (2014) A comparative study on process potentials for frictional stir- and electric hotassisted incremental sheet forming. Procedia Eng 81:2324-2329. https://doi.org/10.1016/j.proeng.2014.10.328

13. Xu DK, Lu B, Cao TT, Zhang H, Chen J, Long H, Cao J (2016) Enhancement of process capabilities in electrically-assisted double sided incremental forming. Mater Des 92:268-280. https://doi.org/ 10.1016/j.matdes.2015.12.009

14. Zhang Q, Xiao F, Guo H, Li C, Gao L, Guo X, Han W, Boundarev $\mathrm{AB}$ (2010) Warm negative incremental forming of magnesium alloy AZ31 sheet: new lubricating method. J Mater Process Technol 210(2):323-329. https://doi.org/10.1016/j.jmatprotec.2009.09.018

15. Ji YH, Park JJ (2008) Formability of magnesium AZ31 sheet in the incremental forming at warm temperature. J Mater Process Technol 201(1-3):354-358. https://doi.org/10.1016/j.jmatprotec.2007.11. 206

16. Nguyen NT, Seo OS, Lee CA, Lee MG, Kim, J. hoon, Kim, H.Y. (2014) Mechanical behavior of AZ31B Mg alloy sheets under monotonic and cyclic loadings at room and moderately elevated temperatures. Materials (Basel) 7(2):1271-1295. https://doi.org/ 10.3390/ma7021271

17. Nguyen DT Park JG and Kim YS, (2010) Ductile fracture prediction in rotational incremental forming for magnesium alloy sheets using combined kinematic/isotropic hardening model. Metallurgical and Materials Transactions A, pp. 1983-1994. https://doi.org/10.1007/s11661-010-0235-1.

18. Bohlen J, Cano G, Drozdenko D, Dobron P, Kainer KU, Gall S, Muller S, Letzig D (2018) Processing effects on the formability of magnesium alloy sheets. Metals (Basel) 8(2):147. https://doi.org/ 10.3390/met8020147 
19. Abbassi F, Srinivasan M, Loganathan C, Narayanasamy R, Gupta M (2016) Experimental and numerical analyses of magnesium alloy hot workability. J Magnes Alloy 4:295-301. https://doi.org/10. 1016/j.jma.2016.10.004

20. Mirnia MJ, Shamsari M (2017) Numerical prediction of failure in single point incremental forming using a phenomenological ductile fracture criterion. J Mater Process Technol 244:17-43. https://doi. org/10.1016/j.jmatprotec.2017.01.029

21. Shalin PM, Harit KR (2019) Numerical investigation on forming behavior of friction stir tailor welded blanks (FSTWBs) during single-point incremental forming (SPIF) process. J Braz Soc Mech Sci Eng 41:424. https://doi.org/10.1007/s40430-019-1929-y

22. Soeiro JMC, Silva CMA, Silva MB, Martins PAF (2015) Revisiting the formability limits by fracture in sheet metal forming.
J Mater Process Technol 217:184-192. https://doi.org/10.1016/j. jmatprotec.2014.11.009

23. Isik K, Silva MB, Tekkaya AE, Martins PAF (2014) Formability limits by fracture in sheet metal forming. J Mater Process Technol 214(8):1557-1565. https://doi.org/10.1016/j.jmatprotec.2014.02. 026

24. Zhan X, Wang Z, Li M, Hu Q, Chen J (2020) Investigations on failure-to-fracture mechanism and prediction of forming limit for aluminum alloy incremental forming process. J Mater Process Technol 282:116687. https://doi.org/10.1016/j.jmatprotec.2020. 116687

Publisher's note Springer Nature remains neutral with regard to jurisdictional claims in published maps and institutional affiliations. 